\title{
A RECUSA ÉTICA NO JOVEM LUKÁCS: CONTORNOS E LIMITES DA SUBJETIVIDADE EM TEORIA DO ROMANCE.
}

\author{
Bruno Moretti Falcão Mendes \\ Universidade Federal de São Paulo
}

Resumo: Para Lukács, o romance caracteriza-se como uma forma por excelência da modernidade exatamente por tornar-se um sistema representativo do caráter fragmentário do momento histórico. Pois bem, torna-se imprescindível articular a problemática do romance moderno com o estatuto do conceito de ironia, pois, pelo recurso irônico subsiste a única possibilidade de conferir sentido e unidade à realidade, já que ao nível da realidade efetiva o sentido não se faz mais presente. Eis a situação complexa do conteúdo da ironia, que permite estabelecer coesão e ordem através da vontade criadora dos ideais subjetivos, seja do escritor, seja do herói moderno no interior da obra, porém, obedecendo à objetividade normativa do romance enquanto gênero épico, a fragmentação do mundo deve estar contida na configuração artística, não havendo, portanto, um desdobramento ilimitado da subjetividade. 0 aspecto composicional do romance movimenta-se na contradição entre a subjetividade criadora - a ética subjetiva do escritor - e as condições objetivas da realidade social fragmentária. A ironia adquire um papel estrutural decisivo para o romance, um intervalo mínimo de recusa crítica ao presente, ainda que de modo abstrato, lírico e reflexivo, porque está radicada em solo subjetivo, pois ela representa o elemento abstrato e reflexivo que mantém o equilíbrio entre a intenção subjetiva do autor e a objetividade do conteúdo. E tal conteúdo é, como dissermos acima, carregado de complexidade. Para Lukács, 0 recurso irônico, enquanto autocorreção da subjetividade, permanece tão subjetivo quanto à própria intenção meramente subjetiva, e faz ressaltar um duplo caráter da subjetividade irônica: a criação da uma realidade formal no interior da obra, tendo em vista que no plano empírico a realidade é impenetrável aos sentidos e que, por conseguinte, torna-se a única via capaz de produzir uma unidade e totalidade. Para Lukás, no paradigmático Bildungsroman Os Anos de aprendizado de Wilhelm Meister, Goethe opera de forma exemplar a homogeneização das estruturas do mundo no interior da obra, por meio da idealização subjetiva do personagem principal e apenas subjetivamente, dado o caráter impenetrável da realidade efetiva. Todavia, a conciliação e totalidade épica levada a cabo no interior do romance não são uma recusa consciente do antagonismo entre o sujeito e o mundo, mas um tensionamento entre ambos. E é esse espaço de recusa do romance enquanto gênero épico comprometido com uma narrativa sobre a realidade objetiva que faz com que Lukács distancie-se da recepção do conceito irônico de Schlegel e difundida no Primeiro Romantismo, fundada no subjetivismo radical e que, segundo Lukács, abstraía o substrato épico do romance, orientando-se unicamente pela via subjetiva da interioridade.

Palavras-Chave: Lukács. Ética. Novela. Subjetividade. Romantismo.

\footnotetext{
${ }^{1}$ Doutorando em Filosofia. Bolsista da CAPES.
}

\section{Blucher}


Young Lukács' ethical refuse:

Traces and limits of subjectivity at the theory of the novel

\begin{abstract}
For Lukács, the novel constitutes a form par excelence of the modernity exactly by becoming a representative system of the fragmentary character of the historical moment. So, it becomes necessary to articulate the problem of the modern novel with the statute of the concept of irony, since, through the ironic resource subsists the only possibility to attribute sense and unity to reality, as far as at the level of the effective reality the sense is no longer present. That's the complex situation of the content of the irony, which allows to establish cohesion and order through the creative will of the subjective ideals, be them the writer's or the modern hero's from inside the oeuvre, although, obeying the normative objectivity of the novel as an epic genre, the fragmentation of the world must be contained in the artistic configuration, not existing, therefore, one unlimited unfolding of the subjectivity. The compositional aspect of the novel moves on at the contradiction between the creative subjectivity - the ethic subjective of the writer - and the objective conditions of the fragmentary social reality. The irony acquires a decisive structural role for the novel, one minimal interval of critical refuse of the present, even though in an abstract mode, lyric and reflexive, because it's rooted in subjective soil, for it represents the abstract and reflexive element which maintains the balance between the subjective intention of the author and the objectivity of the content. And such content is, as we said before, filled with complexity. For Lukács, the ironic resource, as auto correction of the subjectivity, remains as subjective as the merely subjective intention, and highlights one double character of the ironic subjectivity: the creation of a formal reality inside the oeuvre, regarding that on the empirical plan the reality is impenetrable to the sense and that, as a consequence, becomes the only way capable of producing unity and totality. For Lukács, at the paradigmatic Bildunsroman Os Anos de Aprendizado de Wilhelm Meister, Goethe operates exemplary the homogenization os the structures of the world inside the oeuvre, through the subjective idealization of the main character and only subjectively, given the impenetrable character of the effective reality. Although, the conciliation and epic totality taken to an end at the interior of the novel are not a conscious refuse of the antagonism between the subject and the world, but a tensioning between them. And it's this space of refuse of the novel as an epic genre committed with a narrative about the objective reality which makes that Lukács moves away from the reception of the Schlegel's ironic concept and diffused at the First Romantism.
\end{abstract}

Keywords: Lukács. Ethical. Novel. Subjectivity. Romantism. 
A recusa ética no jovem Lukács: Contornos e limites da subjetividade em Teoria do Romance

Quando Lukács ${ }^{2}$, em sua $T d R^{3}$, diz que "a criação das formas é a mais profunda confirmação que se pode pensar da dissonância" (2000, p. 72), estamos diante do entrelaçamento entre questões éticas e estéticas. 0 sujeito artístico põe-se diante do mundo, e em seu ato de construir pela forma um mundo que seja compatível com os seus anseios, confronta-se com o mundo efetivo e descompassado nas relações entre vida e sentido e, neste sentido, no ato de formar do sujeito criador reside o correspondente lastro ético, pois a arte é a tentativa de recobrar a existência efetiva junto às formas do pensamento, diante do desacordo entre o conteúdo efetivo da vida e a forma, buscando recuperar a unidade entre a objetividade e a subjetividade e, "oferecendo à alma expatriada ou exilada uma imagem do mundo que lhe serve de pátria, de realidade conforme à essência humana" (TERTULIAN, 2008, p. 68).

No conjunto de ensaios que constituem A Alma e as Formas (2015) ${ }^{4}$, já está presente um fundamento ético das análises de Lukács que eclode de forma decisiva em $T d R$, que é o conflito entre o mundo alheio a ideias e a alma que não se adequa a este mundo da objetividade cega em

\footnotetext{
${ }^{2} 0$ trabalho aqui apresentado tem como base a tese de doutorado que estamos desenvolvendo junto ao Programa de PósGraduação em Filosofia da Universidade Federal de São Paulo, sob a orientação do Prof. Dr. Luciano Ferreira Gatti. Por ora, tratase de uma apresentação que tem como escopo 0 aspecto mais fundamental que norteia a pesquisa que estamos desenvolvendo, que tem como título, A recusa ética no jovem Lukács: Contornos e limites da subjetividade em Teoria do Romance e apresenta como temática de análise teórica as questões histórico-filosóficas e éticas suscitadas no período da estética de juventude do filósofo húngaro Györky Lukács. Nosso objeto principal de análise é Teoria do Romance e nossas intenções diante da obra voltamse para a análise que Lukács promove acerca da forma do romance, na obra Teoria do Romance, no entrelaçamento com questões éticas. Trata-se de uma tomada de posição de Lukács em face da realidade cindida na experiência social burguesa moderna, ao compreender a experiência subjetiva do romance como uma recusa ética do presente, o que o conduz a uma nova formulação do conceito filosófico de ironia, distanciando-se da tradição do romantismo.

${ }^{3}$ Teoria do Romance, doravante TdR. É importante salientar que nosso trabalho de análise envolve o cotejamento com a versão original em alemão, Theorie des Roman, não encontrada nas bibliotecas do Brasil. No presente projeto, utilizamos a seguinte versão, em larga escala encontrada na biblioteca do Institut für Kulturwissenchaft der Humboldt-Universität zu Berlin: [Lukács, G. Theorie des Romans. Ein Geschichtphilosophischer Versuch über die Formen der grossen Epik. München: DTV, 1994.

${ }^{4}$ Lukács, Georg. A Alma e as Formas. Tradução de Rainer Patriota. Belo Horizonte: Autêntica, 2015.
}

\section{Blucher}


que reina a cisão entre a liberdade na atividade do pensar e o substrato sensível de ação do sujeito. Este é o quadro que marca a tensão entre 0 artista moderno e as estruturas prosaicas e fragmentadas da sociedade burguesa. Dentro desse contexto, é por meio da análise de diversas formas artísticas que Lukács questiona a possibilidade de uma forma autônoma que faça recobrar a vida com um sentido ético, ou seja, trata-se da busca do sentido do mundo por uma via abstrata, formal e subjetiva da produção do espírito.

Nos termos de diagnóstico do presente, estamos diante de um cenário sombrio e desalentador, caracterizado pela dissolução dos vínculos orgânicos nas estruturas sociais e pelo domínio do isolamento individual. 0 descompasso entre a vida e o sentido de ação - o seu critério ético - é a marca de uma crise da cultura que Lukács percebe e aponta por meio de sua crítica de arte $^{5}$. Tal descompasso afeta, tanto o nível dos objetos e aspectos constitutivos do mundo, quanto a perspectiva do sujeito, pois ambas as dimensões não apresentam uma harmonia preestabelecida, e sim uma descontinuidade de elementos heterogêneos, que nos conduz a um conceito-chave que acompanha toda a produção filosófica do jovem Lukács, que é o de Missverständnis, a má-compreensão e a dificuldade de comunicação entre os indivíduos isolados da sociedade moderna. Era preciso buscar algo, reconfigurar subjetivamente a substancialidade épica perdida.

A problemática da sociabilidade moderna nos conduz à questão da exposição das formas artístico-literárias, pois, se por um lado é necessário o cuidado para não estabelecer uma simetria

\footnotetext{
${ }^{5}$ E Lukács a faz em A Alma e as Formas por meio do ensaio, como fica exemplarmente definido no texto célebre que conceitua 0 ensaio como crítica de arte. Dentre o conjunto de ensaios da obra, o destaque em questão fica para o ensaio cujo título é "Sobre a forma e a essência do ensaio: carta a Leo Popper".
} 


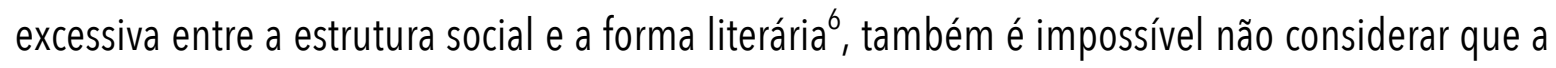
exposição das formas artístico-literárias permite tornar visível e elevar as questões essenciais para o debate estético, qual seja, a do problema da cultura na sociedade moderna, descontínua e crivada no divórcio entre a objetividade efetiva no âmbito do Estado, das instituições e das relações sociais e o outro âmbito, o que reside nos anseios subjetivos, tal qual Lukács opera em TdR. Dessa forma, entendemos as formas estéticas como uma linha mestra de Lukács para a exposição de questões éticas e histórico-filosóficas. Eis a chave para a compreensão da relação entre o plano estético e a fundação ética, fundamental para o nosso caminho a ser percorrido, que será o de delimitar com precisão a tomada de posição de Lukács e sua 'recusa ética', que se em Entwicklungsgeschicht des modernen Dramas (1981) era marcada por um anticapitalismo romântico de inspiração simelliana, em $T d R$, salta aos olhos uma filosofia da história alicerçada na dialética de Hegel.

Tendo esclarecido tais questões, faz-se necessário também penetrar no fundamento teórico do conceito filosófico de ironia, conceito-chave para a compreensão da liberdade propiciada pela forma do romance, bem como da possibilidade de uma recusa do presente por meio de uma ética subjetiva. Em primeiro lugar, ao lançarmos mão do conceito de ironia, delineamos tal conceito a partir da sua natureza, possibilidades e complexificação. 0 conceito de ironia a ser desdobrado por Lukács em $T d R$ envolve, por princípio, o alto grau de complexidade do conteúdo determinante no recurso irônico, como possibilidade de realização do romance enquanto gênero épico. Torna-se necessário salientar as condições que fazem com que o fundamento ético do romance assuma uma

\footnotetext{
${ }^{6}$ Nicolas Tertulian fala de uma transposição "mecânica e brutal" da estrutura social para realidade artística da obra literária que Lukács operava em História do Desenvolvimento do Drama Moderno [Entwicklungsgeschicht des modernen Drama], por meio dos conceitos de Simmel. Cf. Tertulian, Nicolaas, Georg Lukács: etapas de seu pensamento estético, op. cit., p. 69.
}

\section{Blucher}




\section{Bruno Moretti Falcão Mendes}

importância ímpar e mais significativa do que qualquer outra forma artístico-literária do gênero épico, pois, tendo em vista o imperativo normativo do gênero épico como a configuração objetiva das relações sociais - a narrativa sobre a totalidade extensiva da vida - , estamos diante da problemática do conteúdo, que "exige uma colaboração talvez ainda mais explícita e decisiva entre forças éticas e estéticas do que no caso de problemas formais evidentemente puros" (LUKÁCS, 2000, p.71). Tal caracterização acentuada por Lukács é o que distingue o romance da épica antiga, a partir de um duplo aspecto que será aqui sumariamente apresentado: 1) 0 primeiro ponto diz respeito ao núcleo temporal, à especificidade histórica como condição de configuração formal das formas da grande épica. Na épica antiga, o substrato de ação na organização social da experiência grega possibilitava uma organicidade imanente, que contemplaria o sentido ainda no âmbito empírico, sendo possível num arremate meramente formal abarcar a totalidade extensiva da vida. Em termos de valores de referência, prevalece o ideal de comunidade e é desconhecida a figura do indivíduo isolado. Em contrapartida, no romance, o sentido imanente à vida já não se faz presente no plano da realidade empírica. A descontinuidade de elementos heterogêneos é uma característica determinante na solidão moderna, e aqui os anseios do indivíduo isolado não coadunam com as condições objetivas da sociedade civil burguesa; 2) 0 segundo aspecto é a resposta na forma à questão do substrato histórico. Pela convergência imediata entre intenção e realidade, a epopeia fornece um postulado ético puramente formal, já que se trata de uma intenção anterior à figuração pela forma. Na epopeia a forma já está consumada de modo a priori. No romance, todavia, não há mais a convergência entre a intenção e a realidade. A realidade mostra-se descompassada em fragmentos e cabe à subjetividade criadora do artista a coesão homogênea de tais elementos, embora levada à cabo apenas na realidade do mundo do romance, 
na obra. Esta é a ética da formação artística pelo sujeito criador, inserida subjetivamente por meio da própria forma, pois, aqui, já não há mais uma totalidade extensiva que está posta e exprimível a priori pela forma. É preciso a intenção do sujeito em construir por meio da forma uma totalidade fechada e perfeita em si mesma.

Seguindo na perspectiva de análise da forma do romance, 0 ato de formar pelo sujeito criador possibilita coesão e sentido à vida no interior da obra, e apenas por meio dela. Apenas por meio dela porque a ética subjetiva do escritor tem a possibilidade de escapar ao isolamento reinante no cenário desconexo e fragmentário da sociedade burguesa, em que o sentido está ausente. É possível então formar uma estrutura de mundo homogênea e adequada aos anseios da alma do herói, o homem do romance. Pelo pressuposto épico, Lukács diz acerca da intenção normativa do romance que "o ato pelo qual o sujeito confere forma, configuração e limite, essa soberania na criação dominante do objeto, é a lírica das formas épicas sem totalidade" (2000, p. 49). Por ser uma forma em curso, em devir, e não estar já consumada como em outras formas da grande épica, o romance foi qualificado de modo pejorativo como uma "semi-arte" [Halbkunst](2000, p.72; 1994, p.63), por trazer à tona a relação problemática entre ser e devir, fazendo com que o romance represente "um equilíbrio oscilante, embora de oscilação segura, entre ser e devir" (2000, p.73).

Por que então a complexidade da ironia no que diz respeito ao seu conteúdo? É preciso novamente reiterar que, no romance, a possibilidade de consecução de seu imperativo normativo reside em solo subjetivo, ou seja, na ética subjetiva do escritor. Dito isso, apreende-se então 0 fundamento abstrato do romance na subjetividade criadora do escritor, na sua intenção artística em promover uma coesão e sentido. Como já anunciado acima, o escritor cria uma estrutura de

\section{Blucher}




\section{Bruno Moretti Falcão Mendes}

mundo homogênea e conciliável ao sentido. E, a partir dessa realidade já previamente estruturada no mundo do romance é possível a conexão entre os personagens e destes em relação ao personagem central, que projeta perspectiva e limite de extensão ao mundo, a partir de si mesmo, no limite formativo de suas experiências. Tal quadro de conexões torna possível circunscrever 0 mundo em torno do homem do romance.

Convém assinalar que, a obra de Lukács contém uma mudança qualitativa no tratamento da ironia e seus efeitos enquanto figuração da forma artística, pois, se na produção teórica anterior à $T d R$, exemplificada mais especificamente em alguns dos textos que constituem o conjunto de ensaios de A Alma e as Formas, a predileção de Lukács era pela forma do drama trágico, enquanto a ironia era entendida como um sintoma significativo de conformação do eu à realidade, em $T d R$, a ironia passa ser compreendida como um conceito categorial central da forma romance e como índice do caráter cindido da experiência social na modernidade e tais fissuras na experiência social são anunciadas pela experiência subjetiva do romance como desdobramento consciente da subjetividade diante do mundo. Tal desdobramento é o autoconhecimento dos limites entre conceito e realidade, espírito e natureza, alma e vida, ou, em uma linguagem mais própria à $T d R$, como objetividade nos termos da autocorreção ética exigida pela forma.

A ironia passa a ser compreendida como índice de objetividade do romance, como autoconhecimento diante do mundo, reconhecendo-se os limites em se verificar sentido no âmbito da exterioridade. A objetividade aqui destacada é a objetividade como condição de realização épica intrínseca ao fundamento ético - a busca incessante pela pátria utópica perdida -, o que Lukács denomina como "objetividade normativa do criador épico"(2000, p.85), a ética do escritor que coloca o próprio intento ético como objeto de reflexão e torna-se consciente da dualidade entre a 
idealidade 'essencial' e a realidade efetiva. 0 intento subjetivo do criador põe-se se diante de si mesmo, supera-se e nos conduz à relação dialética entre o sistema de ideias e, consequentemente, dos ideais que regulam o mundo do romance e os objetos efetivos a serem configurados pela forma.

A chave que nos permite compreender 0 assento dialético que Lukács promove para 0 conceito de ironia é a liberdade, pois, a ironia é a liberdade de criação para a realidade do romance, mas assentada a um sistema de ideias não circunscrito às condições vigentes na realidade social, o que permite à experiência subjetiva ir além dos grilhões de uma realidade descontínua, fragmentada e recortada pela fratura da alienação entre a reflexão conceitual e o substrato de ação. 0 objetivo utópico não é atingido, e a ideia imanente ao mundo anulada enquanto ideal psicológico da interioridade, sem forças para penetrar no âmbito sensível, mas é uma liberdade criadora que impede que a subjetividade possa situar-se de forma unilateral e isolada, mas tornando-se consciente da fissura inviolável entre ideia e realidade e anunciando um mundo estranho que não satisfaz. Porém, essa luta entre a alma carente de substancialidade e o mundo exterior vazio e descontínuo marca de modo sintomático essa equação problemática entre ser e devir. Apesar de a realidade efetiva vir a se impor a qualquer tentativa de estruturação de uma totalidade utópica pelo romance, pois a problemática normativa do romance está calcada na não conciliação com a vida, o romance revela pela forma uma problemática do mundo, "o verdadeiro estado do espírito contemporâneo" (2000, p.73) como o substrato da objetividade épica normativa do romance e a força de sua forma enquanto "virilidade madura"(2000, p.86).

Portanto, a totalidade épica do romance encontra o seu solo na ética subjetiva para desdobrar-se livremente, colada a uma vida que the é essencial, mas descolada da vida concreta

\section{Blucher}


do mundo exterior. Tal é o fundamento abstrato do romance, mas, que possibilita para a sua forma uma abertura crítica diante do mundo exatamente por enfrentar a questão do descompasso entre o sujeito e o objeto a partir de critérios imanentes à problemática do mundo, não suprimindo a densidade subjetiva presente no fundamento ético do romance e muito menos reduzindo a subjetividade ao critério objetivo como "sentido imanente do mundo objetivo" (LUKÁCS, 2000, p.85). A questão, para Lukács, era a de que o romance anunciava de modo maduro a problemática do mundo e não a exauria segundo fórmulas mistificadoras.

Torna-se necessário também marcar o deslocamento que Lukács promove ao conceito de ironia. Pela lente subjetiva da ética do escritor é possível fornecer unidade na totalidade épica do romance, a partir de uma estrutura de mundo adequada aos anseios da alma do herói. Por meio da figura do herói do romance e de sua perspectiva formativa, o escritor fornece concatenaçã̃o aos elementos do mundo, como recurso para conferir organicidade às estruturas da realidade. São as características do processo biográfico do romance que possibilitam, pela intenção subjetiva do escritor, elaborar uma homogeneização prévia diante das estruturas prosaicas da vida burguesa. Eis as condições e possibilidades de uma totalidade épica fechada e perfeita em si mesma no interior obra.

Tal recurso irônico é levado a cabo por Goethe, em sua obra Os anos de aprendizado de Wilhelm Meister, no sentido de que a configuração de estruturas do mundo no interior da obra está radicada em solo subjetivo, e as transformações e processos por que passa o herói em sua experiência formativa diante do mundo são um artifício do autor para realizar, ainda que abstrata e subjetivamente, o seu intento utópico. Em Goethe, a configuração da realidade sob o prisma subjetivo é, sob as lentes de Lukács, um nível mais elaborado de confronto contra a vida cindida e 
as estruturas prosaicas burguesas, na configuração das relações sociais burguesas. 0 desfecho da trajetória de Wilhelm, sua ocupação profissional 'ideal', que tem em contrapartida a renúncia aos ideais que se agitavam em sua alma na juventude e a adequação ao mundo burguês são, no âmbito da forma, como Lukács bem caracteriza de modo histórico-filosófico, um nível mais aprimorado de tentativa de síntese entre os conflitos subjetivos do sujeito e os aspectos objetivos do mundo exterior, que torna a forma do romance uma forma por excelência da modernidade, "a forma representativa da época, na medida em que as categorias estruturais do romance coincidem constitutivamente com a situação do mundo" $(2000$, p.96).

É aqui, portanto, o ponto decisivo na reelaboração crítica do conceito filosófico de ironia romântica, operada por Lukács por meio de Goethe. Pois, a configuração de elementos da vida burguesa cotidiana, a família, profissão, Estado, objeto de crítica do romântico Novalis, por resultar numa obra antipoética, é exatamente o ponto a favor a ser ressaltado por Lukács. 0 recurso irônico em Goethe é o não descolamento com a realidade social e a configuração da própria realidade no interior da obra intenta o combate contra a vida burguesa e alienada. A crítica ao Primeiro Romantismo e a necessidade de reformulação do conceito de ironia por Lukács dão-se por conta do modo romântico de se opor à vida burguesa, a saber, por meio de um subjetivismo radical incapaz de configurar as relações sociais no contexto da situação histórica, com o seu núcleo temporal. Assim, o romantismo, abstraindo subjetivamente sem reservas todo o conteúdo sensível do mundo, distancia-se do substrato épico do romance, como assevera Lukács.

Em seu ensaio intitulado Sobre a Filosofia Romântica da vida: Novalis, Lukács aponta que uma das características do programa romântico, que tinha como objetivo principal fundar uma cultura harmônica e universal diante do cenário de crise e desagregação já vivenciados no final do

\section{Blucher}


século XVIII, era a necessidade de viver a vida de modo pleno, artisticamente, extraindo e desfrutando de toda a riqueza que a vida poderia fornecer. É nessa perspectiva que a poesia se torna o fundamento do mundo, um pampoetismo no qual "tudo é poesia, e a poesia é o Uno e 0 Todo" (2015, p.90). 0 próprio conceito de poeta [Dichter] e o seu ato de criação artística jamais seriam tão carregados de sentido como foram nos primeiros românticos. Nessa arte de viver, na qual Novalis foi o que levou até as últimas consequências, o caminho não poderia ser outro senão 0 da interiorização, com a recusa do conteúdo concreto da vida. Diz, Lukács acerca da perspectiva que envolveu esses primeiros românticos, que, "0 caminho da interiorização que trilharam só podia conduzir a uma fusão orgânica de todas as coisas dadas, a uma imagem belamente harmoniosa das coisas, não a um domínio das coisas" (2015, p. 90). Assim, para Novalis, o Wilhelm Meister de Goethe só poderia resultar num quadro antipoético do belo. Sobre a crítica de Novalis ao antipoetismo de Goethte, temos a seguir:

Os anos de aprendizado de Wilhelm Meister são de certo modo inteiramente prosaicos e modernos. Nele o elemento romântico cai por terra, e assim também a poesia da natureza, o maravilhoso. Ocupa-se ele meramente de coisas corriqueiras, humanas, a natureza e o misticismo são de todo esquecidos. É uma história burguesa e doméstica poetizada. 0 maravilhoso é tratado expressamente como poesia e exaltação. Ateísmo artístico é o espírito do livro [...] No fundo, [...] ele é apoético no mais alto grau, por mais poética que seja a exposição (NOVALIS, 1978, pp.800-1, pp.806).

Depois de tanta exaltação poética, Goethe, na leitura de Novalis, teria abdicado da "flor azul", esfacelando a imagem harmoniosa das coisas. Mas é nesse ponto que reside a força irônica de Goethe, pois, no Bildusngsroman em questão, não se trata de uma pura reflexão, já que 0 
Willhelm Meister sai a campo, enfrento o mundo em sua tentativa de resolver a dissonância entre o eu e a exterioridade. Segundo Lukács, o romantismo também procuraria, assim como em Goethe, um equilíbrio de forças e uma estrutura harmoniosa do mundo, mas na medida em que as forças da natureza sensível do mundo exterior fossem apenas um espelhamento da reflexão primária e imediata do Eu. Para o romantismo, "o individualismo é mais duro e caprichoso, mais consciente e intransigente que o de Goethe; o romantismo quer atingir a harmonia última com o máximo de individualismo" (LUKÁCS, 2015, p.88).

0 herói do romance de Goethe resigna-se diante do mundo, e tem de adaptar-se a uma realidade efetiva e vencedora, alheia a ideais, ou, como afirma Lukács, um momento limite da reflexão diante do mundo, momento que significa "um abandono da idealidade irreal da alma em prol de um controle da realidade" $(2000$, p. 87). Porém, tal limite diante do mundo consagrado na forma é também uma recusa ao caráter fragmentário da sociabilidade burguesa, cujos valores de referência representam uma verdadeira desorientação nos termos de uma relação da alma com 0 núcleo de essencialidade que a mesma almeja. Diz Lukács:

E na medida em que que configura a realidade como vencedora, a ironia revela não apenas a nulidade do mundo real diante de seu adversário derrotado, não apenas que essa vitória jamais pode ser definitiva e será reiteradamente abalada por novas insurreições da ideia, mas também que o mundo deve sua primazia menos à própria força, cuja grosseira desorientação não basta para tanto, do que a uma problemática interna - embora necessária - da alma vergada sob os ideais $(2000$, p. 87).

A imagem do mundo moderno é a imagem do vazio que se mantém quando o sistema de leis e regras do pensar orientados em torno das determinações espaço-temporais são

\section{Blucher}


instransponíveis ao sentido. No mundo moderno e desencantado, os deuses que conferiam sentido e coerência à imagem do mundo foram banidos para sempre. É necessário então um novo deus enquanto determinação subjetiva. Esse novo deus é o demonismo, o psicologismo do herói romanesco capaz de fornecer novamente sentido e coerência ao mundo.

Para Lukács, tanto a ética subjetiva do escritor (a sua subjetividade criadora) quanto o papel do herói na interconexão entre aventura e destino no mundo romanesco são doadores de sentido. E o elemento irônico do aspecto composicional do romance é o único espaço para se atingir 0 mínimo de essencialidade, ainda que, a exigência crítica no elemento composicional não possa de forma alguma realizar-se como realidade efetiva, mas apenas no âmbito lírico e reflexivo.

0 bom romance seria, para Lukács, aquele que promove o tensionamento com as questões da vida, ou, em outros termos que também atestam como o caráter específico da recepção do conceito de ironia por Lukács distancia-se da recepção romântica, quando diz que o "romance é a forma da virilidade madura: seu escritor perdeu a radiante crença juvenil de toda a poesia, de 'que destino e ânimo são nomes de um mesmo conceito'"' (NOVALIS apud LUKÁCS, 2000, p. 86).

É dentro desse contexto que se torna possível afirmar que o elemento irônico é uma recusa crítica diante da realidade efetiva descompassada, uma "mística negativa dos tempos sem deus" (LUKÁCS, 2000, p. 92). A ironia é uma docta ignorantia em relação à falta de sentido no mundo, por não querer saber essa falta de sentido como verdadeira efetividade do mundo, por resguardar um único fio de substancialidade em um novo deus inexistente, e inexistente pela sua carência em relação ao núcleo temporal da ordenação sensível do mundo. Eis que, por sua negatividade diante do mundo, que se sustenta diante do antagonismo entre a objetividade e a subjetividade, a ironia é 0 índice de objetividade do romance. 
A recusa ética no jovem Lukács: Contornos e limites da subjetividade em Teoria do Romance

\section{Referências Bibliográficas:}

LUKÁCS, Georg. A Alma e as Formas. Tradução de Rainer Patriota. Belo Horizonte: Autêntica, 2015.

- A Teoria do Romance: Um ensaio histórico-filosófico sobre as formas da grande épica. Tradução de José Marcos Mariani de Macedo. São Paulo: Duas Cidades; Ed. 34, 2000, p. 72.

Die Seele und die Formen. Neuwied: Luchterhand, 1971.

. Die Theorie des Romans. Ein Geschichtsphilosophischer Versuch über die Formen grossen Epik. München: DTV, 1994.

. Entwicklungsgeschichte des modernen Dramas. Darmstadt: Luchterhand, 1981.

TERTULIAN, Nicolas. Georg Lukács: etapas de seu pensamento estético. Tradução de Renira Lisboa de Moura Lima. São Paulo: EDUNESP, 2008, p. 68.

NOVALIS. Werke, Tagebücher und Briefe. Munique: Carl Hanser, 1978. 